\title{
Designing of milling tool spindle
}

\author{
Jakeer Hussain Shaik ${ }^{1 *}$ and K. Ramakotaiah ${ }^{2}$
}

\author{
${ }^{I}$ Department of Mechanical Engineering \\ ${ }^{2}$ KKR and KSR Institute of Technology, Guntur, India, 520017
}

Received: 17 August 2017

Revised: 10 October 2017

Accepted: 31 January 2018

DOI: http://dx.doi.org/10.3329/bjsir.v53i3.38265

\begin{abstract}
Analysis of chatter stability in an end milling process is quite cumbersome because of the inaccurate knowledge in the spindle's geometrical design, position of the bearings and several issues related to the spindle structure. The effective position of bearings of the spindle plays a key role in investigating the self-excited chatter vibrations, which requires an accurate transfer function at the most flexibility region of the spindle tool structure. The present work focuses on the development of a novel method of measuring the spindle vibration responses experimentally using sine sweep tests for a CNC end milling machine tool. Using these model data, an analytical model of the spindle is estimated by considering the bearing span as a design variable. Trial runs are conducted until the convergence between the identified transfer function from the model and that from experiment is achieved. The final model of the spindle system is then applied with time-varying cutting forces so as to obtain the process stability.
\end{abstract}

Keywords: Chatter stability; Spindle vibration; Transfer function; Sine sweep tests; Bearing span (BS)

\section{Introduction}

Machining spindles are important rotor dynamic systems requiring enormous attention during the design. In an effort to choose the factors that avoid chatter and to attain the better surface finish, accurate dynamic models of tool-holder-spindle assembly are required. Such a dynamics reflected at tool tip can be acquired by model testing, but entails a large number of tool-holder arrangements in a manufacturing facility. Few studies are reported in view of analytical and experimental works related to modeling of the spindle. The in-depth analysis of the radial stiffness of machine-tool spindles with various effects such as shortening the overhang length or increasing the area moment of inertia of the spindle and the stiffness of the front bearing would enhance the static stiffness of spindle systems (Yang, 1981). The finite element method for modeling of rotor systems (Ruhl and Booker, 1972; Nelson, 1980) includes translational inertia and bending stiffness due to rotational inertia, gyroscopic moments and shear deformation. An empirical formula is developed for the integrated thermo-mechanical dynamic model to calculate the stiffness of bearings (Bossmanns et al., 1999; Lin et al., 2003). A coupled spindle-bearing model that includes thermal effects to predict the bearing stiffness and natural frequencies of the spindle system, using DeMul's bearing model presented by (Li and Shin, 2004). A new technique of determining the transfer function (TF) by utilizing the inverse research of the self-excited vibrations by including finite-element modeling magnetic excitation and inductive displacement measurements of the spindle response (Suzuki et al., 2012; Gagnol et al., 2011; Rantatalo et al., 2007). The reliance of these models were then examined and determined with precision. An (Cao and Altintas, 2007; Cao et al., 2013) updated finite element model is developed to assist the industrial engineers toward attain a reliable model that can accurately represent the dynamic characteristics of machine-tool spindle systems. Different techniques which considered the consequences of multiple-mode features at high excitation frequencies and wide ranges of spindle speed and their

*Corresponding author e-mail: jakeershaik786@yahoo.co.in 
interaction effects were designed (Tanga and Song 2009; Gagnola et al., 2007; Lin and Tu, 2007; Jiang and Zheng, 2010; Hung et al., 2013). The dynamic stiffness of the high speed rotating spindles is obtained by non-contact experimentally measuring methods (Matsubara et al., 2015). In all above works the model analysis were conducted on the spindle unit in no-run condition. But practically the dynamic model parameters will vary according to the changing cutting conditions. The present work estimates the model characteristics while machining at various process parameters. The model parameters are estimated by the Timoshenko beam theory by considering the rotary inertia and shear deformation effects. A series of experiments are conducted to find the dynamic state model parameters.

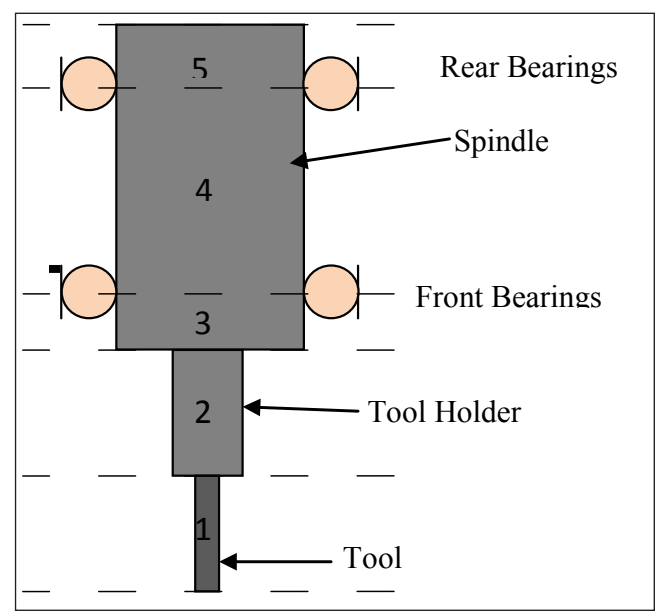

Fig. 1. Equivalent finite element model of spindle tool unit

\section{Modeling of spindle assembly}

Identification of the tool dynamics is very important in high precision applications. Experimental model analysis is commonly used for measurement of input forces and output responses. However, it can be applied only when the machine tool is not in operation. The model data measured at the static

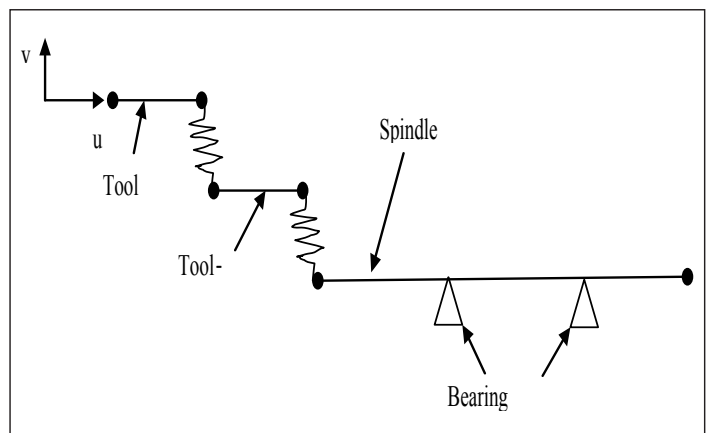

Fig. 2. Equivalent line model of spindle tool unit state would be different from that during cutting operation. The vibration performance of the spindle-tool unit can be effectively recognized by means of confined spindle assembly line model as shown in Figure. 1. All the segments of the spindle-holder-tool are discretized with Timoshenko beam elements incorporating shear deformation and rotary inertia effects.

The entire spindle unit is considered to have five elements with five degrees of freedom per node including one axial motion (u), one bending deflections(v) as well as bending slopes $\left(\theta_{y}, \theta_{z}\right)$ and has total 24 degrees of freedom. It is considered that two nodes of the spindle unit rest on the two angular contact bearings. Tool is supposed to be attached to the tool holder by means of a flexible joint with the help of the two springs in $\mathrm{y}$ and $\mathrm{z}$ direction as shown in Figure 2.

Similarly, the tool holder is also coupled to the spindle shaft in same fashion. The finite element model of the unit can be described (Nelson, 1980):

$$
\left[M_{b}\right]\{\ddot{q}\}+\left[\left[C_{b}\right]-\Omega\left[G_{b}\right]\right]\{\dot{q}\}+\left(\left[K_{b}\right]-\Omega^{2}\left[M_{c b}\right]\right)\{q\}=F(t)
$$

where $\left[M_{b}\right],\left[C_{b}\right]$ and $\left[K_{b}\right]$ are the assembled mass, viscous damping and stiffness $\left[K_{b}\right]$ matrices for the beam element, $\mathrm{W}$ is speed of rotation, while $\left[G_{b}\right]$ represents the gyroscopic matrix and the term $\mathrm{W}^{2}\left[M_{c b}\right]\{q\}$ indicates the softening effect of spring forces.

\section{Ball bearing forces}

The front and rear positions of the spindle shaft are supported by the same angular contact ball bearings. Without

$$
\begin{aligned}
& \mathrm{F}_{\mathrm{x} 1}=-\mathrm{c}_{\mathrm{b} 1} \dot{\mathrm{x}}_{\mathrm{b} 1}-\sum_{\mathrm{i}=1}^{\mathrm{N}_{\mathrm{b}}} \mathrm{k}_{\mathrm{b} 1}\left(\mathrm{x}_{\mathrm{b} 1} \cos \varphi_{\mathrm{i}}+\mathrm{y}_{\mathrm{b} 1} \sin \varphi_{\mathrm{i}}-\delta\right)^{1.5} \cos \varphi_{\mathrm{i}} \\
& \mathrm{F}_{\mathrm{y} 1}=-\mathrm{c}_{\mathrm{b} 1} \dot{\mathrm{y}}_{\mathrm{b} 1}-\sum_{\mathrm{i}=1}^{\mathrm{N}_{\mathrm{b}}} \mathrm{k}_{\mathrm{b} 1}\left(\mathrm{x}_{\mathrm{b} 1} \cos \varphi_{\mathrm{i}}+\mathrm{y}_{\mathrm{b} 1} \sin \varphi_{\mathrm{i}}-\delta\right)^{1.5} \sin \varphi_{\mathrm{i}} \\
& \mathrm{F}_{\mathrm{x} 2}=-\mathrm{c}_{\mathrm{b} 2} \dot{\mathrm{x}}_{\mathrm{b} 2}-\sum_{\mathrm{i}=1}^{\mathrm{N}_{\mathrm{b}}} \mathrm{k}_{\mathrm{b} 2}\left(\mathrm{x}_{\mathrm{b} 2} \cos \varphi_{\mathrm{i}}+\mathrm{y}_{\mathrm{b} 2} \sin \varphi_{\mathrm{i}}-\delta\right)^{1.5} \cos \varphi_{\mathrm{i}} \\
& \mathrm{F}_{\mathrm{y} 2}=-\mathrm{c}_{\mathrm{b} 2} \dot{\mathrm{y}}_{\mathrm{b} 2}-\sum_{\mathrm{i}=1}^{\mathrm{N}_{\mathrm{b}}} \mathrm{k}_{\mathrm{b} 2}\left(\mathrm{x}_{\mathrm{b} 2} \cos \varphi_{\mathrm{i}}+\mathrm{y}_{\mathrm{b} 2} \sin \varphi_{\mathrm{i}}-\delta\right)^{1.5} \sin \varphi_{\mathrm{i}}
\end{aligned}
$$

considering the axial forces and moment loadings of the spindle system, the angular contact ball bearings can be assumed as deep-groove ball bearings and the dynamic problem of the angular contact ball bearing is made as one of the two degrees of freedom. The local Hertz contact forces 
and deflection relationships for a ball with the inner and outer races may be written as a following set of restoring forces:

Here $\delta$ refers to the initial clearance of the bearings, $N_{b}$ is number of balls, $\mathrm{x}_{\mathrm{b} 1}$ and $\mathrm{y}_{\mathrm{b} 1}, \mathrm{x}_{\mathrm{b} 2}$ and $\mathrm{y}_{\mathrm{b} 2}$ are the displacements of mass elements distributed at the front and rear bearing nodes along $\mathrm{x}$ and $\mathrm{y}$ directions respectively, $\mathrm{k}_{\mathrm{b} 1}$ and $\mathrm{c}_{\mathrm{b} 1}, \mathrm{k}_{\mathrm{b} 2}$ and $\mathrm{c}_{\mathrm{b} 2}$ are the stiffness and damping of front and rear bearings respectively, the angle

$$
\varphi_{\mathrm{i}}=\frac{\Omega r}{(R+r)} t+\frac{2 \pi}{N_{b}}(i-1),
$$

(where $\mathrm{i}=1,2, \ldots \mathrm{N}_{\mathrm{b}}$ ) is the angular location of the $\mathrm{i}^{\text {th }}$ ball. Here the term: $x_{b} \cos \varphi_{i}+y_{b} \sin \varphi_{i}-\delta$ is accounted only when it is positive, otherwise it is taken as zero and the bearing races are at loss of contact with bearing balls. An idealized condition is considered in present work with $\delta=-0.05 \mu \mathrm{m}$ and negligible value of bearing damping.

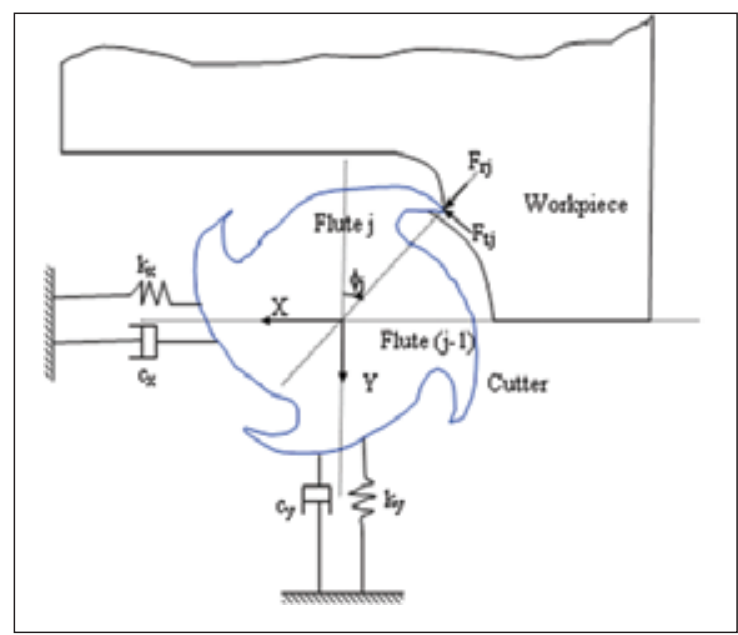

Fig. 3. Two-degree of freedom milling model

\section{Cutting dynamics}

Consider a milling cutter with two degrees of freedom and $\mathrm{N}_{\mathrm{t}}$ number of teeth with a zero helix angle as shown in Fig. 3. The tool is assumed to be compliant relative to the rigid work piece. The vibration is excited by the summation of cutting force.

$$
\mathrm{h}\left(\phi_{\mathrm{j}}\right)=\left(\mathrm{f}_{\mathrm{t}} \sin \left(\phi_{\mathrm{j}}\right)+\mathrm{n}_{\mathrm{j}-1}-\mathrm{n}_{\mathrm{j}}\right) \mathrm{g}\left(\phi_{\mathrm{j}}\right)
$$

If the spindle rotates at an angular speed of $\Omega(\mathrm{rad} / \mathrm{s})$, the immersion angle vary with time as $\phi_{j}(\mathrm{t})=\Omega \mathrm{t}$. The resulting chip thickness consists of a static component $f_{t} \sin \phi_{j}$, where $f_{t}$ is feed per revolution, which is due to rigid body motion of the cutter and a dynamic component $\left(n_{j-1}-n_{j}\right)$ caused by the vibrations of the tool at the present $\left(n_{j}\right)$ and previous $\left(n_{j-1}\right)$ tooth periods. Since the chip thickness is measured in radial direction (n), the instantaneous variable total chip thickness is expressed as:

$$
\mathrm{g}\left(\phi_{\mathrm{j}}\right)=\left(\begin{array}{l}
1, \text { when } \phi_{\mathrm{s}} \leq \phi_{\mathrm{j}} \leq \phi_{\mathrm{e}} \\
0, \text { when }_{\mathrm{j}}<\phi_{\mathrm{s}}, \phi_{\mathrm{j}}>\phi_{\mathrm{e}}
\end{array}\right)
$$

Where the switching function, $g\left(\phi_{\mathrm{j}}\right)$, is equal to one when the $j^{\text {th }}$ tooth is engaged in the cut (i.e., between the cut start and exit angles) and zero otherwise and is expressed as:

$$
\begin{gathered}
\mathrm{F}_{\mathrm{t}, \mathrm{j}}(\phi)=\mathrm{K}_{\mathrm{t}} \mathrm{bh}\left(\phi_{\mathrm{j}}\right) \\
\mathrm{F}_{\mathrm{r}, \mathrm{j}}(\phi)=\mathrm{K}_{\mathrm{r}} \mathrm{F}_{\mathrm{t}, \mathrm{j}}(\phi)=\mathrm{K}_{\mathrm{r}} \mathrm{K}_{\mathrm{t}} \mathrm{bh}\left(\phi_{\mathrm{j}}\right)
\end{gathered}
$$

where $\mathrm{f}_{s}$ and $\mathrm{f}_{e}$ are start and exit immersion angles of the cutter to and from the cut, respectively. The components of linear cutting force in tangential and radial directions $\left(\mathrm{F}_{\mathrm{t}, \mathrm{j}}\right.$ and $\mathrm{F}_{\mathrm{r}, \mathrm{j}}$ ) acting on the tooth $j$ is proportional to the axial depth of cut (b) and chip thickness $\mathrm{h}\left(\phi_{\mathrm{j}}\right)$

$$
F_{x}(\phi)=\sum_{j=1}^{N_{t}} F_{x, j} \quad ; F_{y}(\phi)=\sum_{j=1}^{N_{t}} F_{y, j}
$$

where flute coefficients $\mathrm{K}_{t}$ and $\mathrm{K}_{\mathrm{r}}$ are contributed by shearing in respectively tangential and normal directions. The closed-form expressions for cutting forces are computed by including the summation over all the teeth (flutes) to obtain the total forces as:

\section{Results and discussion}

An experimental model analysis is conducted on the spindle device-tool holder, on the CNC milling centre. The machine tool has 3-axes with a spindle motor having maximum speed of 10,000 rpm. The equipment employed to carry out the model test include:

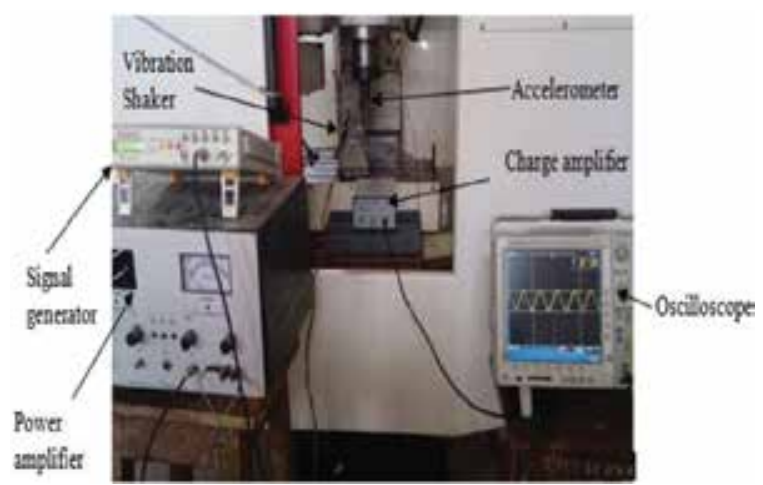

Fig. 4. Experimental set up for model testing of the spindle tool unit 
(i) 4-channel digital oscilloscope (model-DPO 43034 for recording time histories), (ii) power amplifier (modelSI-28), (iii) accelerometer (PG $109 \mathrm{M} 0$, frequency range 1 to $10,000 \mathrm{~Hz}$ ), (iv) charge amplifier (Model: CA $201 \mathrm{~A}$, maximum output voltage- $5 \mathrm{~V}$, frequency range- $0.2 \mathrm{~Hz}$ to $15 \mathrm{kHz}$ ), (v) signal generator and (vi) vibration shaker (Type:V-6-27050) and are shown in Fig. 4.

Sine sweep excitation is applied by varying the frequency of

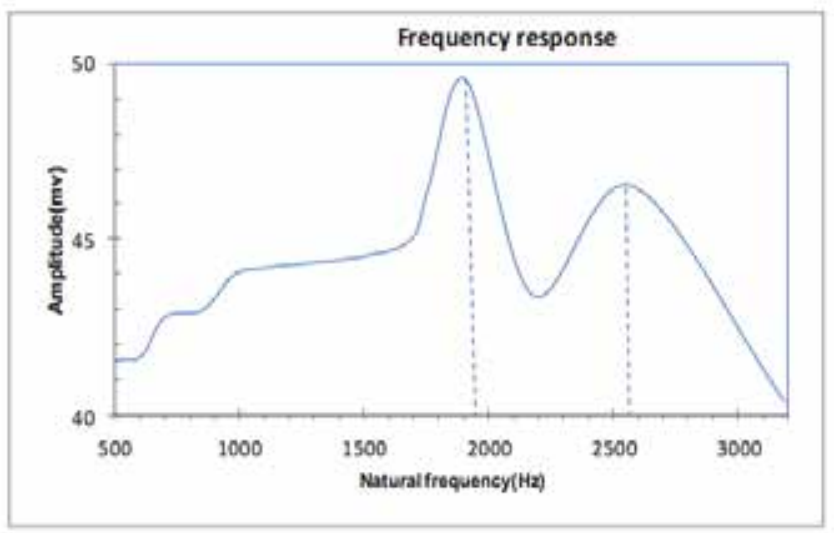

Fig. 5. Frequency response of the integral tool-spindle unit

the signal keeping the signal amplitude constant. The excitation is provided by vibration shaker on the cutting tool and the corresponding accelerometer responses are recorded with the help of oscilloscope at every input frequency level. The amplitudes of response at each frequency are tabulated and plotted as shown in Fig.5. It can be seen that the first two natural frequencies as $1910 \mathrm{~Hz}$ and $2550 \mathrm{~Hz}$ within the sweeping range.

Table I. Parameters of the full-order finite element model
To illustrate the methodology, materials and geometric properties of the individual components are selected from the manual of vertical $\mathrm{CNC}$ end milling machine (MTAB-MAXMILL). The finite element model data of the spindle is illustrated in Table 1. Except the element-1 (tool region with high-speed steel-HSS), all elements have material properties of steel.

In the present work bearing span effect (BS) is considered a dynamic design parameter. The initial dimensions and number of bearing sets were taken from the MTAB CNC milling machine manuals. Afterwards, trail runs are conducted by adjusting the distances between the bearings for different cases. It is evident that the case (e) gives the tool point FRF is in close agreement with experimental model analysis with $\mathrm{BS}=100 \mathrm{~mm}$. Fig. 6(e) represents the FRF by taken the solid damping for the spindle and the peak frequency response is $1908 \mathrm{~Hz}$

The reduced coupled differential equations were solved explicitly, by using Runge Kutta time marching method.

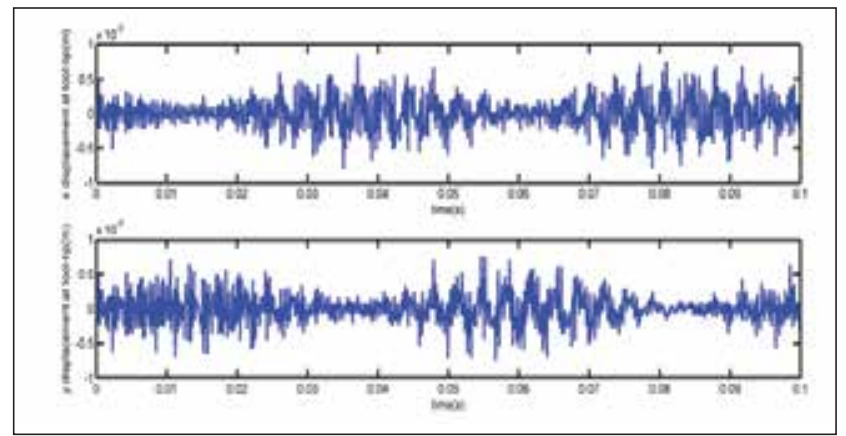

Fig. 7. Time histories at tool-tip mode with external forces

Element of the spindle

\begin{tabular}{lccccc} 
Parameter & $\# 1$ & $\# 2$ & $\# 3$ & $\# 4$ & \\
\hline Length $(\mathrm{mm})$ & 65 & 51 & 111 & 90 & 47 \\
\hline diameter(mm) & 12 & 40 & 75 & 75 & 75 \\
\hline $\mathrm{E}(\mathrm{Pa})$ & $2.8 \mathrm{e} 11$ & $2.1 \mathrm{e} 11$ & $2.1 \mathrm{e} 11$ & $2.1 \mathrm{e} 11$ & $2.1 \mathrm{e} 11$ \\
\hline Density $\left(\mathrm{Kg} / \mathrm{m}^{3}\right)$ & 7972 & 7850 & 7850 & 7850 & 7850 \\
\hline
\end{tabular}




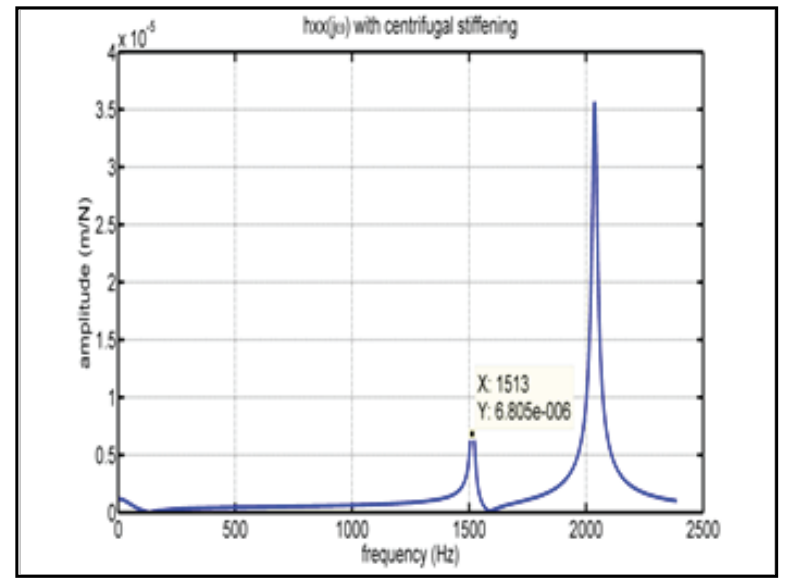

(a)BS of $65 \mathrm{~mm}$

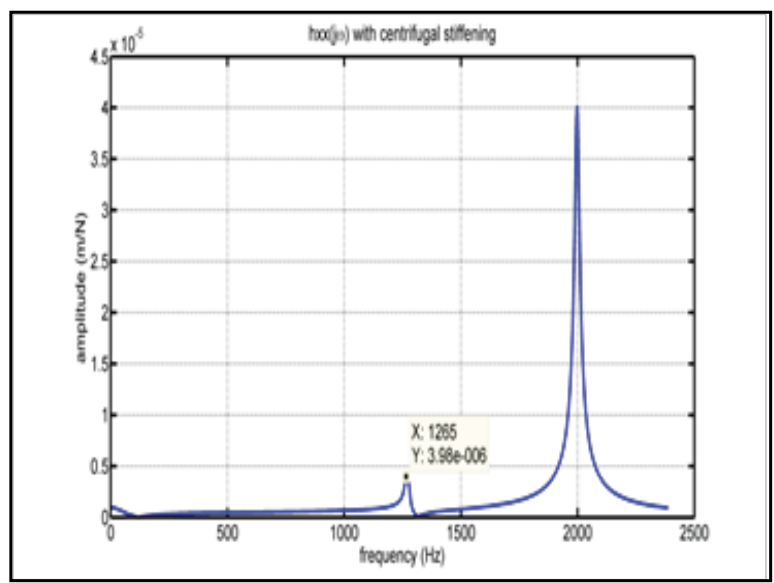

(c) $\mathrm{BS}$ of $80 \mathrm{~mm}$

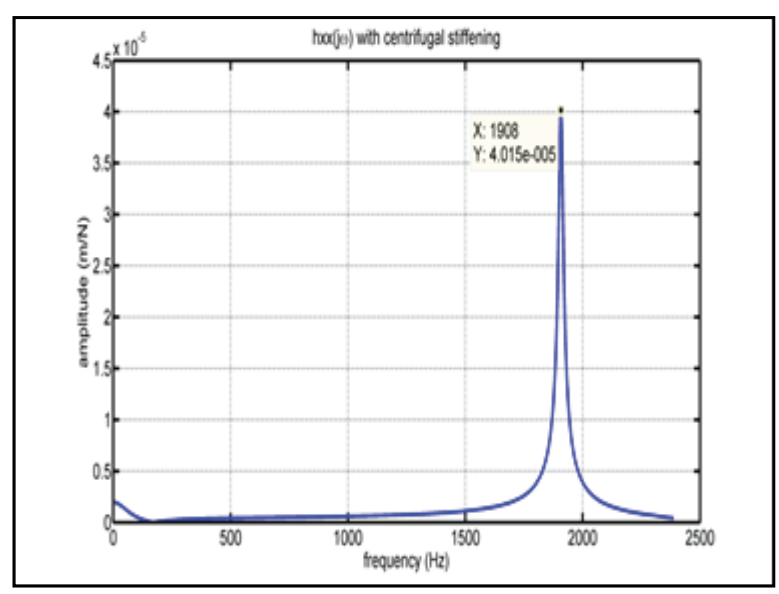

(e) BS of $100 \mathrm{~mm}$

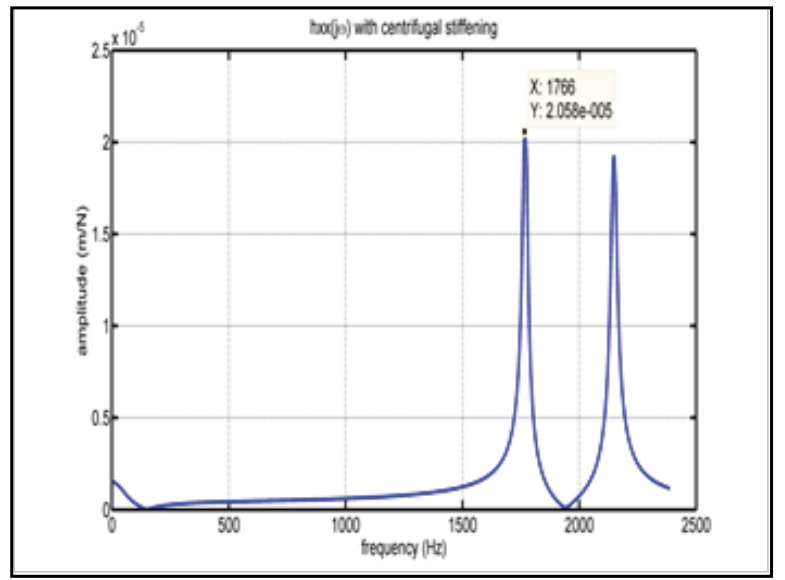

(b) $\mathrm{BS}$ of $75 \mathrm{~mm}$

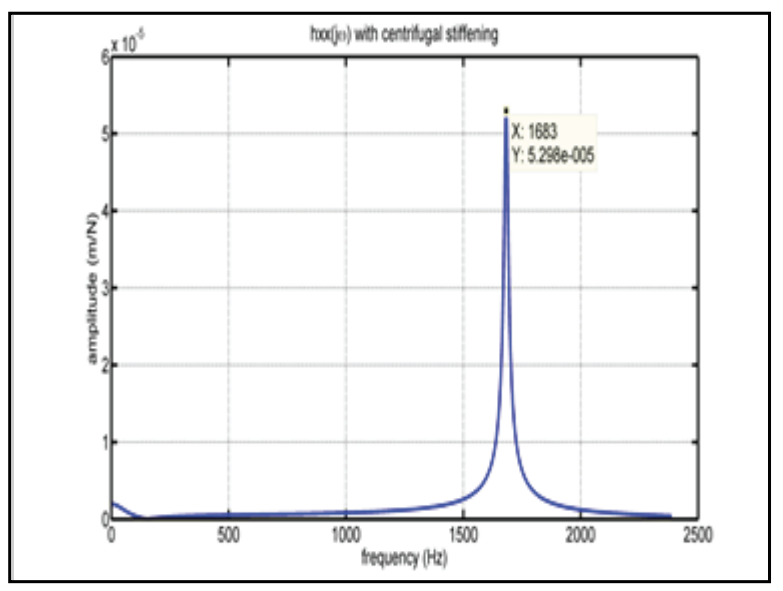

(d) BS of $95 \mathrm{~mm}$

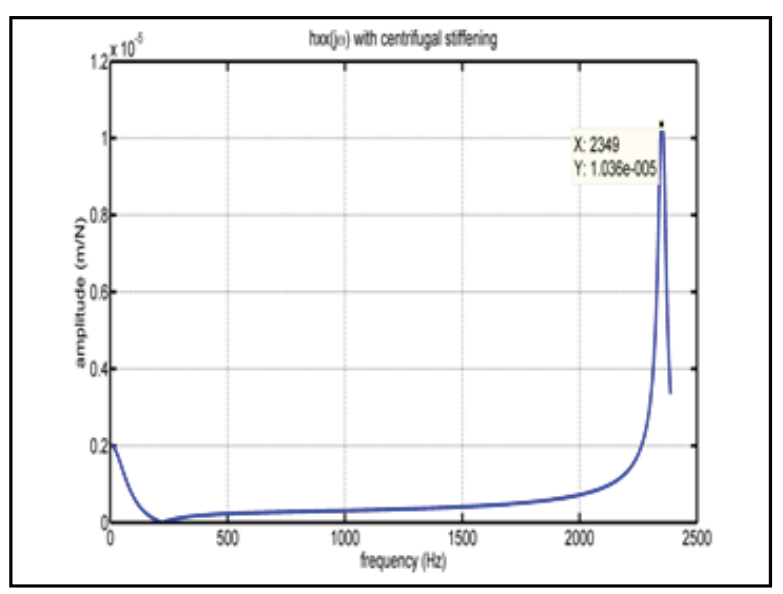

(f) BS of $110 \mathrm{~mm}$

Fig. 6. Tool tip FRF's for different spindle geometric positions 


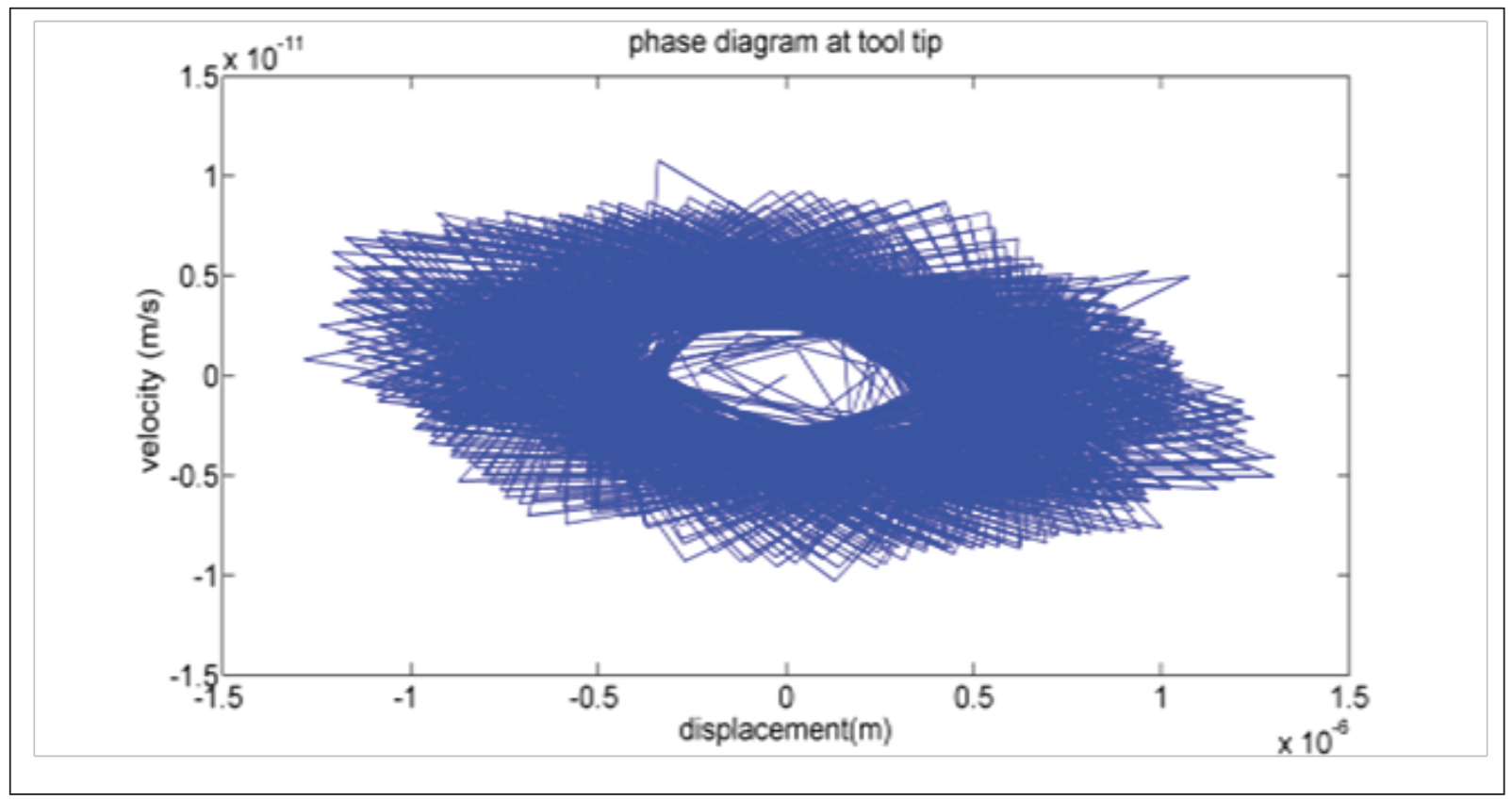

Fig. 8. Phase plot at tool-tip node of the spindle tool unit

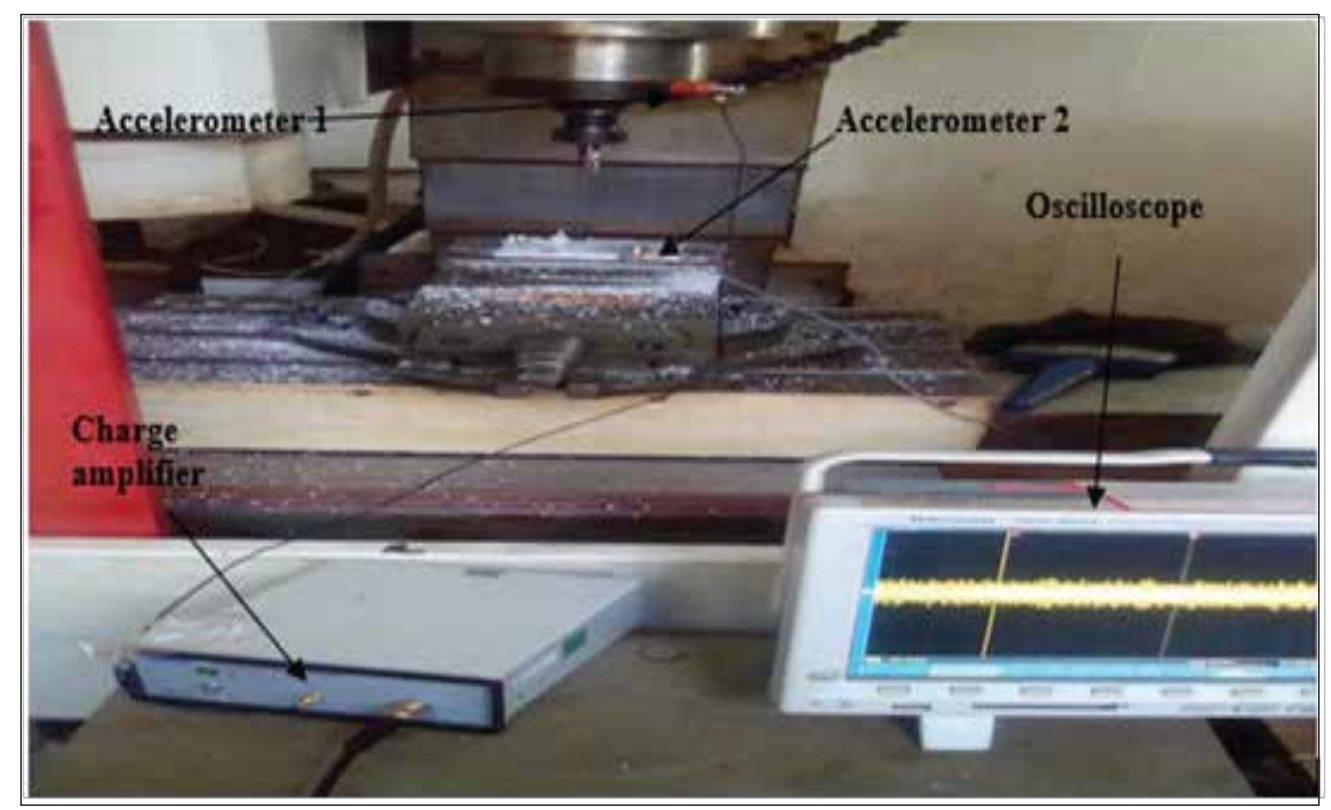

Fig. 9. Experimental set-up employed 


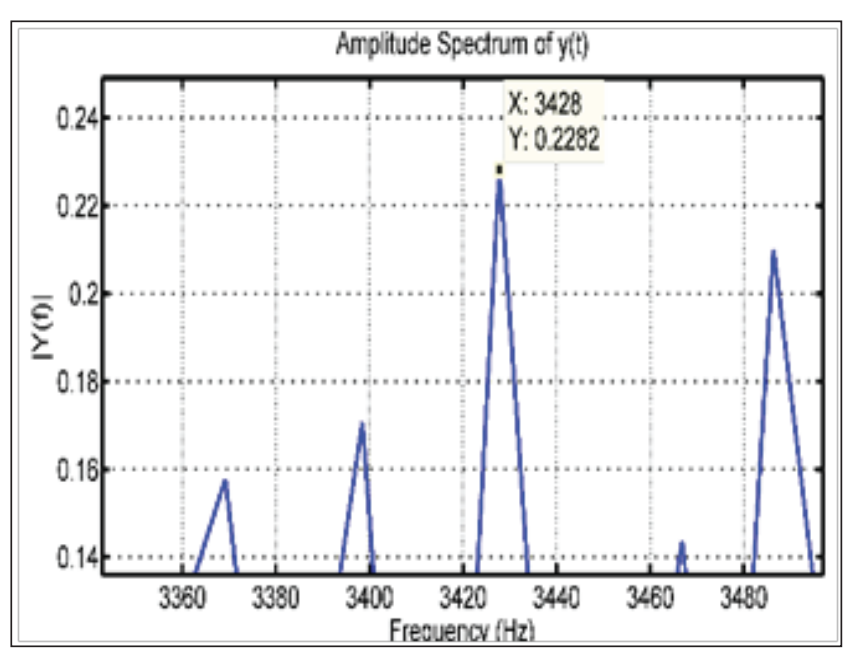

(a) Experimental FFT

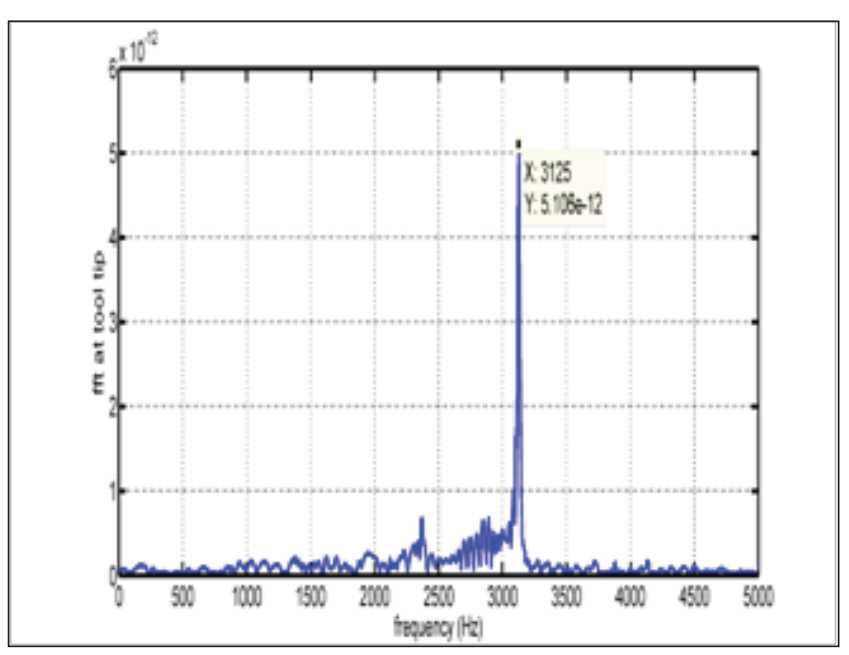

(b) Simulated FFT

Fig. 10. FFT plots from both the experiments and simulation

Fig. 7 shows the time histories at the front and rear bearing nodes corresponding to the following bearing parameters: inner radius $\mathrm{r}=75 \mathrm{~mm}$, outer radius $\mathrm{R}=95 \mathrm{~mm}$, number of ball $\mathrm{N}_{\mathrm{b}}=9, \mathrm{k}_{\mathrm{b} 1}=\mathrm{k}_{\mathrm{b} 2}=13.34 \times 10^{9} \mathrm{~N} / \mathrm{m}^{3 / 2}$, clearance $\delta=-0.07 \mu \mathrm{m}$ (in considering practical conditions, the interference fit generally adapted to chatter problems where negative clearance is justified).

The corresponding phase diagrams are depicted in Fig. 8. As is obvious from phase portraits, the system behaves as periodic with a stable center and it tends move to a chaotic state away from the centre.

In order to ascertain the reliability of dynamic stability of the system, cutting experiments is conducted on CNC milling centre employing the same spindle. The machine tool has 3 -axes with a spindle motor having maximum speed of 4,000 rpm. A High speed steel (HSS) end mill cutter with four flutes having $12 \mathrm{~mm}$ diameter is inserted in tool-holder. Down-milling with slotting is performed on aluminium alloy (Al 3031). The output data for analysis of abnormal vibrations during cutting process at specified speeds, feeds and depth of cut are recorded using a 4-channel digital oscilloscope (Tektronix-43034), with two accelerometers and a charge amplifier as shown in Figure. 9.

lots are shown are shown in Fig. 10(a) for an axial depth of cut of $0.5 \mathrm{~mm}$, Feed of $20 \mathrm{~mm} / \mathrm{min}$ and a spindle speed of 2600. Using the same cutting parameters analytically FFT is arrived as shown in Fig. 10(b).
It is observed that the multiple peaks are arrived in experimental FFT because of the chatter phenomenon during cutting process.

\section{Conclusion}

In the present work a practical model of the spindle tool unit is considered for the analysis using the finite element analysis with Timoshenko beam theory. Experimental model analysis data on the spindle device-tool holder is used to fit the correct finite element model by varying the bearing distances appropriately. Once the model is ascertained, the nonlinear cutting forces and bearing forces are applied and dynamic responses were obtained. The stability assessment is made based on an experimental analysis while machining with a set of operating parameters. The results are some way very interesting and facilitate in controlling the vibration levels during cutting.

\section{References}

Bossmanns B, Tu JF and Kamman J (1999), Thermal model for high speed motorized spindles, International $J$. Mach. Tools Manuf 3: 1345-1366. DOI.org/ 10.1016/S0890-6955(99)00005-X

Cao H, Li B and He Z (2013), Finite Element Model Updating of Machine-Tool Spindle Systems, Journal of Vibration and Acoustics 135: 0245031-0245034. DOI: $10.1115 / 1.4023045$ 
Cao Y and Altintas Y (2007), A general method for the modelling of spindle-bearing systems, J. Mech. Des. Transactions of the ASME 126: 1089-1104. DOI:10.1115/1.1802311

Gagnol V, Phu LT and Ray P (2011), Model identification of spindle-tool unit in high-speed machining, Mechanical Systems and Signal Processing 25: 2388-2398. DOI.org/10.1016/j.ymssp.2011.02.019

Hung JP, Lai YL, Luo TL, and Su HC (2013) Analysis of the machining stability of a milling machine considering the effect of machine frame structure and spindle bearings: experimental and finite element approaches, Int. J. Adv Manf technology 68: 2393-2405. DOI 10.1007/s00170-013-4848-6

Jiang S and Zheng S (2010), Dynamic Design of a High-Speed Motorized Spindle-Bearing System, Journal of Mechanical Design ASME 132: 0345011-0345015. DOI:10.1115/1.4001109

Li H and Shin YC (2004), Integrated dynamic thermo-mechanical modeling of high speed spindles, part 1: Model development, J. Manuf. Sci. and Eng., Transactions of the ASME 126:148-158. DOI:10.1115/1.1644545

Lin CW and Tu JF (2007), Model-Based Design of Motorized Spindle Systems to Improve Dynamic Performance at High Speeds, Journal of Manufacturing Process 9:94-108. DOI.org/10.1016/S1526-6125(07)70111-1

Lin CW, Tu JF and Kamman J (2003), An integrated thermo-mechanical dynamic model to characterize motorized machine tool spindles during very high speed rotation, International J. Mach. Tools Manuf 43: 1035-1050. DOI.org/10.1016/S0890-6955 00091-9
Matsubara A, Tsujimoto S and Kono D (2015), Evaluation of dynamic stiffness of machine tool spindle by non-contact excitation tests, CIRP Annals Manufacturing Technology 64: 365-368. doi.org/ 10.1016/j.cirp.2015.04.101

Nelson HD (1980), A finite rotating shaft element using Timoshenko beam theory, ASME J. Mech. Des 102: 793-803. DOI:10.1115/1.3254824

Rantataloa M, Aidanpaab JO, Goranssonc B and Normand P (2007), Milling machine spindle analysis using FEM and non-contact spindle excitation and response measurement, International Journal of Machine Tools \& Manufacture 47: 1034-1045. DOI.org/10.1016/ j.ijmachtools.2006.10.004

Ruhl RL and Booker JF (1972), A finite element model for distributed parameter turbo rotor systems, ASME Journal of Engineering for Industry 94(1): 126-132. DOI:10.1115/1.3428101

Suzuki N, Kurata Y, Kato T, Hino R and Shamoto E (2012), Identification of transfer function by inverse analysis of self-excited chatter vibration in milling operations, Precision Engineering, 36: 568-575. DOI.org/10.1016/j.precisioneng.2012.04.004

Tanga WX and Songa QH (2009), Prediction of chatter stability in high-speed finishing end Milling considering multi-mode dynamics, Int. J. Machine Tools \& Manf 209: 2585-2591. DOI.org/10.1016/ j.jmatprotec.2008.06.003

Yang S (1981), A study of the static stiffness of machine tool spindles, Int. J. Mach. Tool Des. Res 21: 23-40. DOI.org/10.1016/0020-7357(81)90011-1 